Schimanski et al., (2018). "Promoting Collaborative Construction Process Management by means of a Normalized Workload Approach." In: Proc. $26^{\text {th }}$ Annual Conference of the International. Group for Lean Construction (IGLC), González, V.A. (ed.), Chennai, India, pp. 764-774. DOI: doi.org/10.24928/2018/0488Available at: www.iglc.net.

\title{
PROMOTING COLLABORATIVE CONSTRUCTION PROCESS MANAGEMENT BY MEANS OF A NORMALIZED WORKLOAD APPROACH
}

\author{
Christoph P. Schimanski ${ }^{1}$, Carmen Marcher $^{2}$, Patrick Dallasega ${ }^{3}$, Elisa Marengo ${ }^{4}$, \\ Camilla Follini ${ }^{5}$, Arif U. Rahman ${ }^{6}$, Andrea Revolti ${ }^{7}$, Werner Nutt ${ }^{8}$ \\ and Dominik T. Matt ${ }^{910}$
}

\begin{abstract}
The research project »COCkPiT« - Collaborative Construction Process Management aims at developing methodologies and tools to enhance time and budget control in construction projects, with a focus on small and medium-sized companies. The hypothesis is that the interplay of the three main phases of project management - planning, scheduling, and monitoring - can be improved by collecting highly detailed information early on in each phase, and making it available to the other phases at a high frequency. COCkPiT builds upon previous experiences in façade installation, where significant time and cost savings have been obtained by applying a normalized workload approach based on a collaborative process planning routine, an approach which is currently hardly supported by commercial project management tools. Thus, the objective of COCkPiT is to develop a methodology that supports i) collaborative process modelling as a basis for ii) a short-term rolling wave planning considering iii) real-time measurement of the progress on-site, to create highly reliable schedules and accurate forecasts. The focus of this paper is to present the conceptual fundamentals of integrating the modules of modelling, scheduling and monitoring, as well as involving the lean construction community to current considerations regarding the implementation in a self-containing IT-solution.
\end{abstract}

\footnotetext{
Research Associate, Fraunhofer Italia Research, Bolzano, Italy, christoph.schimanski@fraunhofer.it Research Associate, Fraunhofer Italia Research, Bolzano, Italy, carmen.marcher@ fraunhofer.it Assistant Professor, Faculty of Science and Technology, Free University of Bolzano, patrick.dallasega@unibz.it Assistant Professor, Faculty of Computer Science, Free University of Bolzano, elisa.marengo@ unibz.it Research Associate, Fraunhofer Italia Research, Bolzano, Italy, camilla.follini@ fraunhofer.it Research Assistant, Faculty of Science and Technology, Free University of Bolzano, ArifUr.Rahman@unibz.it Freelance Engineer and Architect in Trento, Italy,andrea.revolti87@ gmail.com

Full Professor, Faculty of Computer Science, Free University of Bozen-Bolzano, Bolzano, Italy, nutt@inf.unibz.it Head of Fraunhofer Italia, Fraunhofer Italia Research, Bolzano, Italy, dominik.matt@ fraunhofer.it Full Professor, Faculty of Science and Technology, Free University of Bozen-Bolzano, Bolzano, Italy, dominik.matt@unibz.it
} 


\section{KEYWORDS}

Collaboration, Production System Design, Process modelling, Job sequencing, Monitoring

\section{INTRODUCTION}

In traditional construction projects, budget overruns are often identified too late, which hinders the effective application of recovery actions. This is partly caused by a coarse planning and management of the construction execution process. The Italian construction industry consists of a great amount of small and medium sized companies (SMEs) that makes the sector highly fragmented (Cacioli, 2017). In consequence, in construction projects most of the participating companies are crafts with an artisanal organizational structure. Therefore, limited resources are available for planning and managing the execution process. Moreover, stakeholders are often characterized by limited knowledge about construction management theory and sophisticated IT-tools for planning and management of the execution process. The management of a construction project is traditionally organized in three main phases (Sears et al., 2008): 1) planning, 2) scheduling and 3) monitoring. Planning is usually managed by considering historical experiences without involving the responsible actors for execution, resulting in schedules with unreliable information(Jeong et al., 2016). Scheduling and assignment of tasks onsite then are mostly carried out in a non-systematic way or even just by acclamation of the foreman(Dallasega et al., 2018). As a result, the focus on value adding tasks and the optimal saturation of workers on-site is seldom achieved(Dallasega et al., 2018). Moreover, a non-structured and detailed scheduling of tasks to be performed on-site makes it difficult to request the right type and quantity of material when it is needed(Bell and Stukhart, 1986; Dallasega and Rauch, 2017).Monitoring of a construction project in a SME context is generally done by rough progress estimations of the foreman on-site. By operation of law, other important information, like workers present on-site, detailed labour-consumption, descriptions of performed tasks as well as weather conditions are recorded in the so-called construction log-book. However, this information is neither recorded in a quantitative way nor connected directly to the construction schedule (Dallasega et al., 2016).As a result, a frequent comparison of scheduled and actual data is not possible.

As a reason for these current weaknesses, the presenting researchers have identified a lack of systematic work planning and schedule routines which incorporates also an exact progress monitoring and is at the same time suitable and accessible for SMEs by means of easy-to-use IT-tools. The research questions thus arising, is to define the methodological foundations for such a system and how it must be designed in order to address SMEs requirements and to integrate it into their day-to-day business. The here proposed methodology consists of a normalized workload approach embedded in collaborative planning routines, which is aimed to be transferred into a supportive ITsolution. 


\section{STATE OF THE ART}

At present, there are several production planning systems flying the flag of the lean movement, aiming to make work plans in the construction domain more reliable and robust, to increase productivity, to minimize waste and ultimately to contribute to satisfying project results from the customer's perspective. In this context, one of the most frequently used method in the execution phase of a construction project is the Last Planner System (LPS) (Kenley and Seppänen, 2010 in Gao and Low, 2014, 1261). LPS, as a method for work planning and control (Ballard, 2000a), aims at creating and managing networks of commitments of involved players for successful project delivery. Process stability and thereby schedule reliability are indicated by means of the Percent Planned Complete value (PPC), which is the percentage of actually-fulfilled to committed-to-be-fulfilled tasks with respect to a defined timeframe. Hence, in an ideal but unrealistic - case, the PPC value would be always $100 \%$. In addition to this methodological approach, LPS also includes a social process that can lead to open discussions among the parties and companies involved, joint learning for continuous improvement and an increase in mutual trust (Gao and Low, 2014). However, even though LPS has been applied successfully in numerous construction projects(Kim and Ballard, 2010; Lindhard and Wandahl, 2013), accompanied by significant process improvements, more predictable workflows and increased schedule reliability, it does not offer a direct possibility to measure progress in absolute numbers and therefore cannot be used as a stand-alone approach for monitoring and coordination of the construction site.

Recently, LPS has been applied with the so-called Takt Planning (TP) approach which is referred to as a work structuring method (Bolviken et al., 2017; Frandson et al., 2014).According to Frandson et al. (2014) LPS and TP are mutually supportive. TP could expand the mechanism of commitment management of the LPS by means of standardized work batches striving to continuous work flow(Frandson et al., 2014). By aiming at disruption-free handovers between trades, TP would methodologically represent a $100 \%$ PPC approach in the LPS perspective (Bolviken et al., 2017).The formal methodology of TP consists of a clocked scheduling where so-called "time-harmonized" work sequences are used to coordinate activities. Therefore, construction projects are structured into "Takt zones" where repeatable and non-repeatable construction elements are defined previous to execution(Altner, 2016). The rhythm of the construction progress is defined by the "Takt time" principle known from lean management (Altner, 2016). For reasons of practicability, a typical order of magnitude for Takt times in the construction domain is one working week (Altner, 2016). In each Takt zone, there is only one trade working at the same time for a precisely defined period of time, which reliably avoids mutual obstructions and reduces the control demand for site management(Altner, 2016). When all involved trades consent to the alignment to a common work rhythm with a corresponding amount of work and work sequences, a very continuous working speed can be achieved (Haghsheno et al., 2016).Insufficiency of this approach consists of the nearly exclusive applicability to repetitive construction works that consist of almost identical work sequences with high recurrence rates (Haghsheno et al., 2016). Nonetheless, recent efforts have been made trying to find some repetition in non-repetitive construction 
works on the basis of work density to solve this problem (Tommelein, 2017). However, practical applications of such cannot be found often and the conceptual framework is not available in textbooks yet (Tommelein, 2017).

Another production planning system that is highly regarded but also used primarily in repetitive construction projects is the Location-Based Management System (LBMS) as a recent methodology based on Location-Based Planning (LBP). As opposed to activitybased methods (i.e. CPM, PERT), LBP focuses on tasks that repeat in different locations to reduce the movement of resources in space. Thus, location is considered a critical variable, on par with time and activities (Kenley and Seppänen, 2010). LBMS has been proven successful at implementation in reducing project duration and balancing resource usage (Seppänen et al., 2014). Nonetheless, the methodology does not consider learning from process feedback for optimizing the planned schedule and updating the forecast(Dallasega et al., 2018), since Kenley and Seppänen (2010)argue that, the learning curve in construction operation remains mostly linear after the very first improvement. Moreover, to a similar extent as TP, LBMS can also be considered complementary to LPS, since LPS covers social aspects in a production planning system, which are being mostly neglected in LBMS (Seppänen et al., 2010). The overlooking of these social considerations makes either LBMS or TP less suitable in the context of SMEs, where fragmentation of actors working on the project, and thus communication and sociality, are crucial factors.

\section{THE COCKPIT PROJECT}

The here proposed approach for an improved Collaborative Construction Process Management (COCkPiT) respects the advantages of the Lean Construction methods presented above, as well as adapts and expands them by significant new aspects.

\section{APPROACH AND COMPARISON TO THE STATE OF THE ART}

Looking at LPS, essential for its successful application is an appropriate definition of the single tasks at the execution level by the Last Planners. Ballard(2000)mentions the following important features: (1) The task must be well defined, (2) tasks must be arranged in the right sequence, (3) the selected extent of work must be right and (4) defined tasks must be feasible. But even underlying these principles, the open question remains: How do we have to specify workloads quantitatively? The COCkPiT approach proposes a normalized workload approach (NWA) which consists in the first step of collaborative estimation of production rates and association of required number of workers for each task as well as work sequencing considering the expertise of Last Planners. This step is termed modelling. Production rates are then normalized to a certain time interval (e.g. one working day). This principle of normalizing workloads is referred to as "pitching" known from Lean Manufacturing and has already been worked out in previous studies and successfully applied to façade construction(Dallasega et al., 2018, 2015). The dimension of the pitch for a specific construction area (CA), and a respective task, considering the associated quantities and crew size for a certain time interval, is the following: 


$$
\text { Pitch }_{\text {CA }_{i} \text { Task }_{j} \text { Crewsiza }_{k}}=\frac{\text { Quantity }_{i j}\left[\mathrm{MU}_{j}\right]}{\text { time interval }}
$$

The dimensional analysis in formula (1) denotes the definition of a pitch as the quantity indicated in the respective measuring unit (MU) of the task $j$ (e.g. $20 \mathrm{~m}^{2}$ of parquet) that can be installed by the dedicated crew of the size $k$ (e.g. two workers) in the CA $i$ (e.g. floor 1) within a defined time interval (e.g. one working day).

$$
\text { Pitch }_{\text {Floor 1,Parquet laying. } \mathbf{z}}=\frac{20 \mathrm{~m}^{2}}{\text { working day }}
$$

An inherent advantage of the NWA over LPS is that the job assignments have a clearly defined measurable and understandable extent in terms of both labour demand and quantities to be installed. The precognition of single and total quantities (e. g. via quantity take-off from BIM models) enables accurate determination of the construction progress at any time in almost real time (on condition that the extent of the pitch completion is reported daily). Extending a production system like LPS with this essential functionality, known key performance indicators (KPI), such as PPC describing process stability, can be maintained without incident. Analogies of NWA to TP can be seen apparently, whereby the chosen time interval (e.g. one working day) can be interpreted as the Takt time in which one pitch of a certain task should be fulfilled. Notable difference to TP here is that after one "Takt", the crew does not have necessarily to move on to the next planned location, given that the number of pitches varies from different trades and CAs. This results in a high degree of flexibility, which in turn does not limit the applicability of the presented approach to repetitive projects only, but potentially also suits non-repetitive projects. At the same time, however, high degrees of freedom in terms of project type require great diligence and coordination work to parallelise and balance the workers on the construction site to achieve a continuous workflow that considers the varying "pitchload" of the individual CA's and trades. To this end, the approach of collaborative process planning with responsible Last Planners is pursued with similarities to the phase scheduling of LPS. However, work structuring in the modelling module of NWA represents a clear distinction to LPS' phase scheduling, since reference is made to normalized production rates independent from durations, whilst LPS' phase scheduling explicitly foresees the application of durations to each activity (Ballard, 2000b). Moreover, the exact labour demand is considered from the beginning on and not just assigned during execution. To further illustrate this difference, Figure 1 was created on the basis of Ballard's (2000a) well-known scheme of the LPS. 


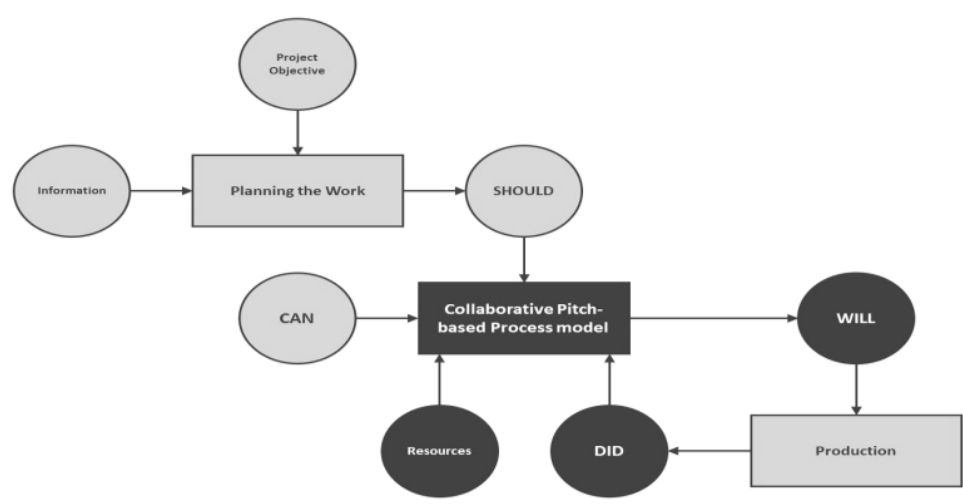

Figure 1: COCkPiT approach - representation based on Ballard(2000a)

The process model forms the basis for automatic scheduling, which respects previously defined dependencies and constraints of tasks and locations. The subsequent monitoring during execution incorporates systematic feedback loops to update initially estimated production rates and labour consumption automatically in the model (pitch update), which in turn triggers a very targeted continuous improvement process (CIP). In addition, employees' confidence in the methodology is systematically increased, because the generated schedules for defined short-term look-ahead windows only include an extent of work that corresponds to their own performance that has so far been monitored. If daily goals defined by the pitch cannot be met, analogously to LPS, reasons for noncompletion (RNC) can be collected, bringing with it all well-known advantages in terms of enhanced transparency and CIP. The schematic flow of the NWA in the COCkPiT project is illustrated in Figure 2, indicating also the feedback loop by means of the monitoring module.

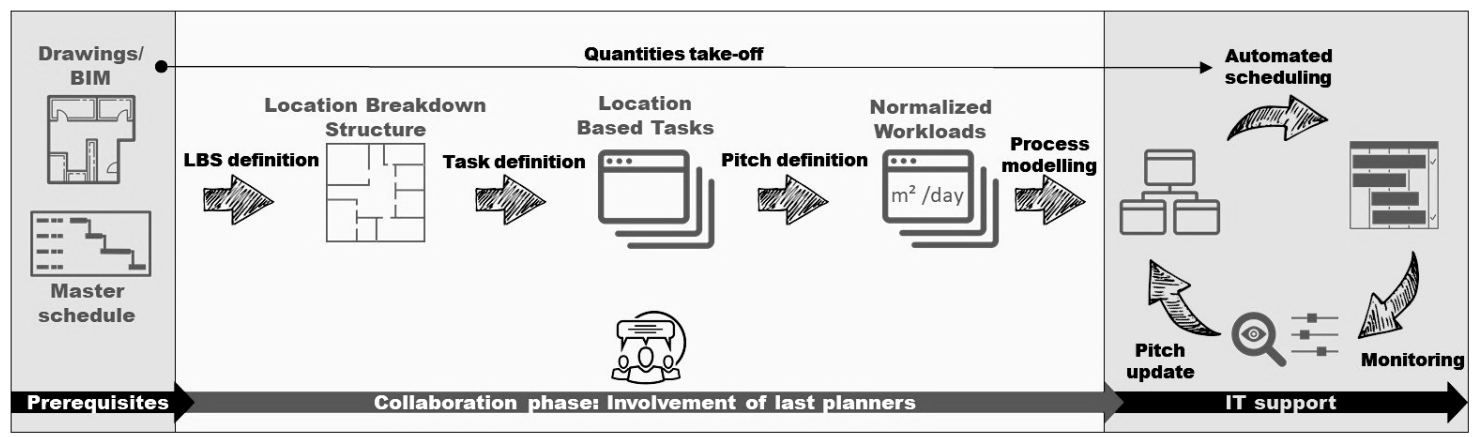

Figure 2: Schematic workflow of NWA

\section{OBJECTIVES}

Within the presented research project, it will be aimed at covering the three main building phases: shell, envelope and interior. The main outcomes to this project will be a NWAbased methodology, as the theoretical framework for an ensuing IT-prototype, to support three main aspects: i) a modelling of the process, comprehensive of all relevant project information, ii) a short-term scheduling module, suggesting possible schedules 
automatically, which are computed based on the information in the model in (i), and iii) a real-time progress monitoring tool, to both control the site operations and progressively adjust the model (i), and subsequently the schedule (ii) to the concretely achieved pace.

The modelling module foreseen in COCkPiT aims at supporting the collaborative definition of the execution process. More precisely, this corresponds in defining i) the main tasks that need to be executed, and for each of such tasks ii) the resources required by it, iii) the locations where to perform it, iv) the pitch, and v) the dependencies (such as precedencies) on the execution of the tasks in the locations.

The aim of the project is to develop a methodology and a formal framework supporting the definition of a process model. This latter is often ignored in construction, where a process is modelled by directly defining a plan. The difference is that a process model would represent only the requirements that a plan must satisfy (e.g., task A must be performed in location 1 any time before task B is performed there), without already committing to sequences and dates on the execution of the tasks. The definition of a model involves different competences from the different trades participating to the project. Therefore, great benefit can be achieved if it is defined collaboratively. To this aim, within the project a graphical language to support a process model definition will be defined, along the line of Marengo et al. (2016).

In the scheduling module, based on the process model collaboratively defined, shortterm schedules can be derived. A short-term schedule represents a commitment to one among the possible plans compliant to a process model. To compute the duration of a task and the number of labour resources needed, the system relies on the concept of pitches defined in the process model, which contains implicitly the commitment of the executors due to its collaborative, bottom-up determination. Importantly, the schedule for a certain period is based on up-to-date information on the executed tasks (information that is collected in the monitoring phase). The project aims at developing IT-tools for this module, both supporting a manual definition of a schedule and automatic generation of them (optimizing some criteria of interest). This will be done by relying on constraint satisfaction techniques.

The monitoring module aims to control the construction progress in a quantitative way and in a real-time frequency. Here, the pitches will be used to measure the construction progress by collecting information with regards to which extent the pitch of every activity has been actually achieved. Up to now, experiences with façade installations(Dallasega et al., 2015)showed that in repetitive working environments the construction progress measurement could be performed by considering the measuring units of single façade fields. In a non-repetitive working environment, a project with a high variety of construction locations, in terms of size and technology content, differentiated units of measurement must be determined. Here, the aim is to define for every task applicable measuring units (like number of pieces, square meters and running meters). Moreover, pitches are used not only to measure the construction progress in a quantitative way but also to forecast in a reliable way the labour demand until project completion. Previous research has shown, that by applying the pitching concept to forecast the labour demand until project completion, the planned and used amount of 
budgeted men-hours can be kept in sync and as such budget overruns can be avoided (Dallasega and Rauch, 2017).

\section{RESEARCH METHODOLOGY}

To increase the practical feasibility of the project outcome, SMEs from Northern Italy have been engaged in the research stage. Hence, the COCkPiT project follows an applied research approach, which was initiated with a preceding literature review and anew analysis of the previous application of NWA in façade installations (Dallasega et al., 2015). As a following step interviews with the industry partners were held to investigate and analyse the current way of working in their represented domain by studying a variety of historical reference projects with a special focus on production planning. The results from this analysis phase were then used for deriving requirements for a methodical and IT-based implementation of the NWA approach as starting point for the conceptual development, which took also into account the previous findings from facade installations(Dallasega et al., 2015). These efforts resulted in a first prototype as MS Excel workaround which will be used as a basis for further development. For this purpose, an agile development approach is pursued, which enables the research team to quickly deliver testable intermediate results and to react very flexibly to the changing requirements derived from field tests. Field tests are currently being initiated in two case studies: (1) renovation of a fire station and (2) construction of a winery (both located in South Tyrol, Italy). In this way a high acceptance of the future system of the industrial partners is expected. As a final result a web based software is targeted, which will be validated through pilot construction sites at the end of the project. The research methodology and process is visualized in Figure 3.

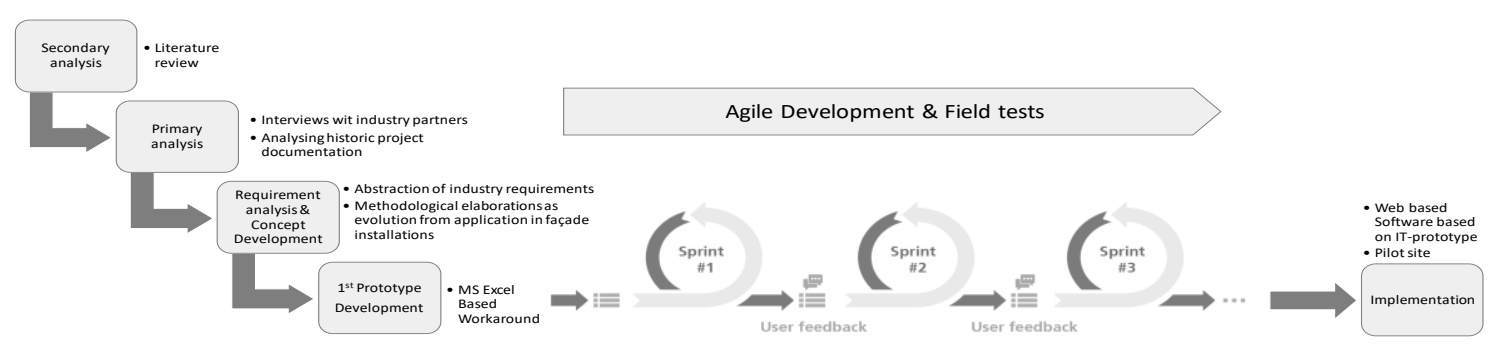

Figure 3: Research process

\section{CONCLUSION \& OUTLOOK}

In this paper, the COCkPiT project and the underlying methodology of a normalized workload approach incorporated in the three modules of modelling, scheduling and monitoring as well as the general research approach were introduced. The here presented current study as part of the entire research project familiarizes the Lean Construction community with the general concept of NWA and investigates the applicability of the methodology and the usability of the first IT-prototype (as a MS Excel workaround) through field tests with the industry partners to (1) proof the general concept and (2) trigger the upcoming agile software development cycles. 
The presented workaround prototype (Figure 4) provides for the modelling of location based construction tasks in an MS Excel sheet, which is used as input by a constraint solving engine. Based on a-priori defined constraints (task and location dependencies) and external conditions (e.g. minimize overall duration or optimal resource saturation) schedules are automatically generated, which in turn are converted into an MS Excel sheet. This sheet is then used on the construction sites for work planning and progress monitoring. Eventually it will be used in a short-term cycle to update the model data.

Preliminary feedback acknowledged the benefits of a model that supports automatic scheduling. However, it was argued that the modelling part should take place as far as possible in the backdrop and that later working with the tool should recall as much as possible the handling of a Gantt chart. It follows that in the coming development sprints, attention must be paid to the effects of user events (influences of changes to the Gantt chart representations on the underlying model) and how the model data can be brought into the system in the simplest and most intuitive way possible.

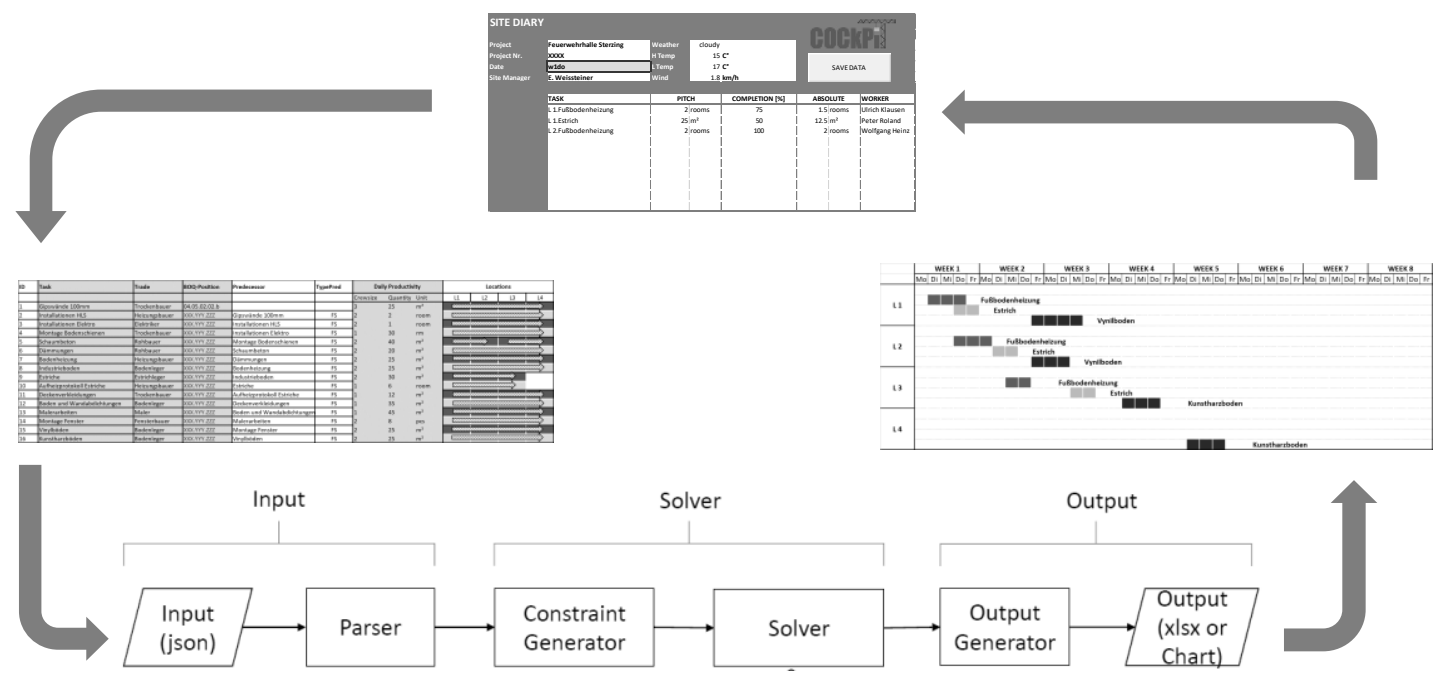

Figure 4: Prototype Workaround

In this respect, the current study will provide valuable guidance, which will be followed and refined in the upcoming sprints. Furthermore, this study serves as a basis to find out how the pitches for the different trades must be defined so that the work can be reliably planned and measured, since the pitching concept is new to most of the participating trades.

\section{ACKNOWLEDGEMENTS}

»COCkPiT« - Collaborative Construction Process Management - FESR 1008 - is a research project financed by the European Development Fund (ERDF) Südtirol/Alto Adige - Axis 1 Research and Innovation. The authors would also like to thank the involved companies Unionbau $\mathrm{GmbH}$, Atzwanger AG and Frener \& Reifer GmbH for their valuable and non-remunerated contribution from a practitioner's perspective to the research project. 


\section{REFERENCES}

Altner, J., (2016). "Effizienter Bauen nach den Grundsätzen von Lean Construction.". $<$ http://leanmagazin.de/lean-praxis> (Nov 18, 16), (in German).

Ballard, G., (2000a). The Last Planner system of production control.PhD Diss., University of Birmingham.

Ballard, G., (2000b). Phase Scheduling. White Pap. No. 7. San Francisco: Lean Const. Inst.

Bell, L.C., Stukhart, G., 1986. Attributes of Materials Management Systems. J. Constr. Eng. Manag. 112, 14-21.

Bolviken, T., Aslesen, S., Kalsaas, B.T., Koskela, L., (2017). A balanced dashboard for production planning and control. Proc. 25th Ann. Conf. Int'l. Gr. Lean Constr., Heraklion, Greece. pp. 621-628.

Cacioli, P., (2017). Ann. Stat. Ital.<http://istat.it/it/files/2015/12/Asi-2015.pdf> (Sep 22, 17).

Dallasega, P., Marcher, C., Marengo, E., Rauch, E., Matt, T., Nutt, W., (2016). A Decentralized and Pull - Based Control Loop for on - Demand Delivery in Eto Construction Supply Chains. Proc. 24th Ann. Conf. of the Int'l. Group for Lean Construction.Boston, USA, pp. 33-42.

Dallasega, P., Marengo, E., Nutt, W., Rescic, L., Matt, D.T., Rauch, E., (2015). Design of a Framework for Supporting the Execution-Management of Small and Medium sized Projects in the AEC-industry. 4th International Workshop on Design in Civil and Environmental Engineering, Taipei, Taiwan, p. 12.

Dallasega, P., Rauch, E., (2017). Sustainable construction supply chains through synchronized production planning and control in engineer-to-order enterprises. Sustainability, 9, 1888.

Dallasega, P., Rauch, E., Frosolini, M., (2018). A Lean Approach for Real-Time Planning and Monitoring in Engineer-to-Order Construction Projects. Buildings, 8, 38.

Frandson, A., Berghede, K., Tommelein, I.D., (2014). Takt-Time Planning and the Last Planner. Proc. 22th Ann. Conf. of the Int'l. Group for Lean Construction. International Group for Lean Construction, Oslo, Norway, pp. 571-580.

Gao, S., Low, S.P., (2014). Lean construction management: The Toyota way, 1 st ed. Springer Science+Business Media, Singapur.

Haghsheno, S., Binninger, M., Dlouhy, J., Sterlike, S., (2016). History and Theoretical Foundations of Takt Planning and Takt Control. Proc. 24th Ann. Conf. Int'l. Gr. Lean Constr., Boston, USA, pp. 53-62.

Jeong, W.S., Chang, S., Son, J.W., Yi, J.S., (2016). BIM-integrated construction operation simulation for just-in-time production management. Sustainability, 8, 1106.

Kenley, R., Seppänen, O., (2010). Location-based Management for Construction: Planning, Scheduling and Control, 1st ed. Spon Press, Abingdon.

Kim, Y.-W., Ballard, G., (2010). Management Thinking in the Earned Value Method System and the Last Planner System. J. Manag. Eng. 26(4), 223-228.

Lindhard, S., Wandahl, S., (2013). Improving Onsite Scheduling: Looking Into the Limits of Last Planner System. Built Hum. Environ. Rev. 6, 46-60. 
Marengo, E., Dallasega, P., Montali, M., Nutt, W., (2016). Process Modelling in Construction: a Formal Approach. 28th International Conference on Advanced Information Systems Engineering, Ljubljana, Slovenia, pp. 1-15.

Sears, K., Sears, G.A., Clough, R.H., (2008). Construction Project Management A Practical Guide to Field Construction Management, 5th ed. John Wiley \& Sons, New Jersey.

Seppänen, O., Ballard, G., Pesonen, S., (2010). The Combination of Last Planner System and Location-Based Management System.Lean Constr. J. 43-54.

Seppänen, O., Evinger, J., Mouflard, C., (2014). Effects of the location-based management system on production rates and productivity. Constr. Manag. Econ. $32(6), 608-624$.

Tommelein, I.D., (2017). Collaborative takt time planning of non-repetetive work. Proc. 25th Ann. Conf. Int'l. Gr. Lean Constr., Heraklion, Greece, pp.745-752. 